\title{
FUTURISTIC TECHNOLOGY IN ARCHITECTURE \& PlanNing - Augmented AND VirTuAl REALITY: AN OVERVIEW
}

\author{
Pearl Jishtu ${ }^{1}$ and Madhura A Yadav ${ }^{2}$ \\ ${ }^{1}$ Student of Fifth year School of Architecture \& Design, Manipal University Jaipur \\ DehmiKalan, Off Jaipur-Ajmer Expressway, Jaipur - 303 007, Rajasthan, India \\ ${ }^{2}$ Professor Manipal University Jaipur DehmiKalan, Off Jaipur-Ajmer Expressway, Jaipur \\ - 303 007, Rajasthan, India
}

\begin{abstract}
Speed has become a way of life. We are asymptotically piling data. Speed can be achieved with new design processes, techniques, and Technology. Innovations AR and VR are just some of the many forms of technologies that will play a key role in shaping the Architecture and Planning of tomorrow, making it future-ready and ushering in a new age of innovation. AR and VR in Architecture \& Planning were introduced as assisting tools and has helped generate multiple design options, expanded possibilities of visualization, and provided us with more enhanced, detailed, and specific experience in real-time; enabling us to see the resultsof work on hand well before the commencement of the project. These tools are further developed for city development decisions, helping citizens interact with local authorities, access public services, and plan their commute. After reviewing multiple research papers, it had been observed that each one is moving forward with the changes brought by it, without entirely understanding its role. This paper provides a summary of theappliance of $A R \& V R$ in architecture and planning.
\end{abstract}

\section{KEYWORDS}

Virtual reality (VR), Augmented reality (AR), Architecture, Urban Design, Human Computer Interface (HCI).

\section{INTRODUCTION}

The process architecture and urban design reckon on including data collection and analysis, design decision, visualization, and evaluation. For all these stages, collaboration and immersion are other steps enabled with AR's introduction to analyze and achieve the best design outcome efficiently. Some of these processes are already in the application. The utilization of this simulation for client-professional design communication is one aspect. However, now it's also being evolved for multiple other applications like public involvement in design decisions, for better ideation by students in the field of design, and improved analysis for policymakers. A study of various research papers was conducted and summarized to review and analyze simulated or algorithmic tools' current developments. The papers cover diverse topics under theory, concept, systems, tools, applications, and implications.

\section{Methodology}

The research paper summarizes the utilization of AR (Augmented Reality) and VR (Virtual Reality) in the field of architecture and urban design, for an in-depth understanding of the 
International Journal on Soft Computing, Artificial Intelligence and Applications (IJSCAI), Vol.10, No.1, February 2021

potentials and challenges of the technology. The research's main objective is to record the progress of these tools with a perspective specific to the design field and to understand its diverse applications. Various research papers on the subject compiled the information cited, of various scholars, published in conferences and readily available on the research websites. The keywords were used to search for the subject related papers and were then studied for a better understanding of the same.

\section{LiteratURE STUDY}

(Seichter et al. 2005) [5] Elaborated research for a better immersive and collaborative means by introducing the Human-Computer interface, they see the need for collaboration between the realtime and virtual designs in a better collaboration for increased performances. 'Sense of presence' is discussed regarding it as a vital aspect of urban design. The importance and methods of immersion are discussed, though the impact of these immersions is not known. The term Phenomenology is introduced and discussed in regards to Human-Computer Interfaces (HCI) and urban design. Phenomenology- the principle of empirical observation on events based on different theories but cannot be directly explained, as per various theories that have been put forth by Husserl and Gibson (1931) [1], Schutz and Northwestern University (1967) [2], and Norman (1988) [3], about the connection between perceivably real and virtual objects. Discussing the intangible connections between real and virtual objects to establish a conscious sense of presence. (i) Human-Computer Interfaces (HCI), of which AR and VR are the main components, having greater scope in the field of urban design and architecture (Frazer et al. 1980)[4]. They expand the horizon of workability and expression by bringing the real and virtual together in one interface compared to the limited experience of the physical models. Their inherent physical nature makes them easy to understand by the layman and the experts alike, although some technical issues still exist in the system's dynamic nature. However, AR offers a spread of opportunities where urban design can gain from the intersection of both the real and virtual realms. (ii) Collaboration and cognition being vital in urban designing, invoke the utilization of immersive technology and perceptible interlinking. (iii) Cognition is the ability to comprehend and create a comparison amongst the available data through analysis. This enhances the design understanding and its relationship within the urban context; site-specific contexts are better recognized, and various options can be investigated in no time. As AR permits a blending of virtual entities with the real environment, it can increase the comprehension of the design proposal. (iv) The students and teachers explore innovation- Dynamic and spatial relationships in theory and practice to identify how they can help create and communicate during the initial design ideas by employing AR. Designers gain a more complex understanding of their design relationships and engage in a richer communication with their partners. AR contributes to urban design in an innovative approach, thus enabling new sorts of design expressions.

(Sørensen, 2006) [6] States that Augmented Reality (AR) is a mediating tool to design ideas between the design and a person. The paper provides us with a report on the AR system components, wherein he discusses the technological and physical challenges that might arise during the onsite applications. The possible positive implications of the successful application of the system are discussed. Moreover, the areas that require improvements and research are identified for future research. The paper is an excellent source of information for the practical application and the various components required for the conduct. AR in principal; (i) To overlay data in real-time, the position registration system is required for geo-location of the 3D model or the contextual site. For interiors, infrared, ultrasound systems, or graphical markers system are explored with limited installation time, while in the exterior application includes a differential GPS, (ii) User's angle of view and his position requires an orientation registration system. The limitations include slow data processing, lagging results and inaccuracies in reading data, leading 
International Journal on Soft Computing, Artificial Intelligence and Applications (IJSCAI), Vol.10, No.1, February 2021

to disproportionate models in the surrounding, and (iii) Display device - there are multiple viewing options, one of them being a headset currently has two different systems of operating. One consists of a transparent screen with the model visual, and in the other, the surrounding images are fed to the AR system without the transparent screen. The paper concludes with an analysis of certain limitations of AR Systems in Architecture and Urban Design; poor visualization due to minor reception of the system's markers, caused by the sun glare, while dynamic AR error has been noted with the receptiveness of visual markers. AR promises to induce new insights in architectural learning, introducing the students to new parameters that will enable them to immerse in their designs virtually. This will enable them to study alternatives at different abstraction levels, thus contributing in a better way to the earlier design phases. Dynamic models and collaborative systems will broaden the scope, making it possible to change proposed structures or models in AR, and one could now experience the simulation of changes in physical conditions, animate, being able to visualize pollution, noise, etc.

(Döllner et al. 2006) [7] Discusses the importance and methods of gathering geo-data information for urban planning and redevelopment. Various standards are mentioned along with the software LandXplorer that was released during 2005. The paper provides an insight into different data visualization techniques while representing geo-information structures on 3D city models. Integrated comprehensive systems like virtual city 3D models are utilized to derive diverse urban space information. The application of this standardized model is discussed in various fields that require the visual representation of the urban environment. It is a virtual representation of the building, vegetation models, roads/transportation systems and terrain aiming to incorporate; (i) Cadastral data - delivers footprints of land ownership, ownership status and buildings, (ii) Digital terrain model and photo visualization, (iii) 3D Building model geometry captured by laser-scanning and photogrammetry based methods, and (iv) and historical references with architectural elements. A standardized system for creating these models does not exist, but some of the systems in use include CityGML, 3D Studio Max object files and VRML files, ESRI Shapefiles. This collaborative tool is a great support system for design decision making and covers functionality like managing, integrating, and distributing complex geoinformation supporting a consistent communication metaphor, the virtual 3D city model. These functions are then further divided into sub-systems for content authoring, editing, storing, and presentation extendible 3D city model system. Besides, the automated mapping of 2D landscape plans and architectural plans to 3D virtual environments based on a heuristic-algorithm approach is investigated.

(Seichter, 2007) [8] Discusses a wide range of aspects in regard to AR and VR for the field of design, he introduces multiple visualizations for architecture and elaborates tangible user interfaces. The observations suggested that new techniques and tools to understand the interspatial relation better are beneficial for design, with a better and effective output. The co-located collaborative design process was explored using 3D models and AR tools, while user response was collected with experiments in the field of physical design engagement, communication and the concept of presence. Factors of directness and tangibility of the user input device helped distinguish two experimental conditions. The observations suggested that new techniques and tools to understand the inter-spatial relation better are beneficial for design, with a better and effective output. Novel methods like the TUI have been adopted to link bridges between virtuality and Reality. This investigation provides scope as an opportunity for future development in incorporating such technical interfaces to reach a collaborative setting with consideration for the presence and human perspective.

(Wang, 2009) [9] elaborates on the multiple software/hardware and their various applications and challenges, specifically in architecture and design. The paper shifts the perspective of the AR and 
International Journal on Soft Computing, Artificial Intelligence and Applications (IJSCAI), Vol.10, No.1, February 2021

VR to be developed or researched for a designer. The relation between MR (Mixed Reality), VR (Virtual Reality) and AR (Augmented Reality) is discussed, while further elaborating upon their applications, challenges and potentials in the field of design. Hardware and software are discussed for the various stages of design regarding their current application; Sketchhand+, AR CAD (Augmented Reality Computer-Aided Design), Benchworks, ARTHUR, BUILD IT, MRCVE (Mixed Reality-based Collaborative Virtual Environment), Studierstube and TINMITH2. A lot of research and development has been made in AR and VR simulations, but for specific applications like urban design and architecture, the field is yet to be explored in detail. Leading causes of this domain stagnation include (i) due to unavailability of well organized integrated and immersive 3D database of mechanical services, lack of industrial domain knowledge, (ii) creating a definitive reality model, and (iii) the robustness and the accuracy of the tracking systems. Since the system is not very specific and flexible in current use and needs a pre-analysis of the environment. The future robust AR aims to have a system that could work in unstructured indoor and outdoor environments.

(Abboud, 2014) [10] His research is a holistic compilation of the opportunities created by AR's involvement throughout the various design stages in architecture, i.e. Design, Construction and Post Completion. It discusses the challenges and the solutions to overcome them by increasing portability, improving geo-locating, etc. The paper discusses all of these under an organized format and thus accessing the information becomes methodical and logical in an efficient way. A wide range of toolsets generates $\mathrm{AR}$ and VR simulations, out of which the mobile augmented reality (MAR) is widely explored. MAR system covers diverse applications in vital stages of a project; design, during construction and post-construction. These include (i) initial design decisions or interactions with consultants, clients and designers, (ii) overlaying BIM data, to avoid any later stage accidents, to guide through types of equipment and direct to safety zones in case of an emergency. It Labours can be aided with intricate work with in-situ visual assistance. Project management can be overseen with an onsite model, with data of work progress, and (iii) Post-Completion the facilities to maintain the building structure can take the aid of the augmented system to locate the services and facilitate the maintenance requirements. However, these MAR applications face technological, social and financial issues which need to be resolved before moving forward. Tracking systems need to be evolved and specific for locating services; specialists will have to train the workers with these systems, and new protocols will have to be implemented for maximum efficiency.

(Seichter, 2020) [11] Discusses the challenges and scopes faced by the technology of creating large-scale digital models for urban design and elaborates majorly with the Benchmarks and toolkit utilization. The diverse applications are elaborated in detail while describing the components of the software system. The paper is great for wanting to explore the working of Benchworks. Visualization of the urban data is explored beyond while incorporating the tangible and non-tangible features essential to understanding human interaction in an urban space. The interaction techniques and technologies incorporate the significant contribution of BenchWorks that is collaborative and immersive AR-enabled working environment. BenchWorks is developing the tools and technologies to provide an immersive AR experience specifically for Urban Design data collection and analysis. Their Benchmark sketchbook+ has turned out to be a handy tool for the initial design decision making process.

ARToolKit[12] Provides an easy way to create input devices that do not rely on wires and are, therefore, more convenient in a multi-user setup. The magnet track provides higher precision for head orientation and provides a more stable augmented vision. Significant benefits for this early prototype are combined: the precision of a magnetic tracking system and the freedom of tangible interfaces overcome occlusion within the scene. 
International Journal on Soft Computing, Artificial Intelligence and Applications (IJSCAI), Vol.10, No.1, February 2021

Shared Tangible City - The choice and combination of media play a vital role in investigating space and, subsequently, architecture. BenchWorks goes beyond that, creating a toolkit for investigating a site's spatial feature dynamically in a setting with local and remote collaboration capabilities. In BenchWorks, the user can design by representing the city's void and non-void spaces, adding volumes and making notes; the interaction is tight-knit with tangible interfaces. The toolkit uses two different tools: toolbox and the modifiers represented by pens and the sponge.

(Kim et al. 2011) [13] The paper throws light on the progress of research and implementation of the AR applications in design. The authors summarise the research conducted during the period 2005 - 20011, providing us with the holistic development of AR, wherein it discusses the domain knowledge and human factor consideration in the tools. Provides us with an introduction to shared learning as an essential part in urban design, where students are conversant in syntax and grammar. To understand complex relationships, spatial and dynamic use of AR is employed, which helps people understand urban issues in a new and creative way. AR conceptualization provided with an in-depth understanding of the modelling and algorithmic framework adopted and the challenges faced due to sun glare (Chung et al. 2009) [14], temporary lags created in the systems (Wang and Dunston 2005) [15], heavy equipment (Santos et al. 2007; Chung et al. 2009) [16][14] and therefore the human factor. These concepts and ideas implemented with hardware or software tools that have their challenges like(i) the human interaction is not very experiential, (ii) potential use of agent-based is yet to be explored (Belcher and Johnson 2008)[17], and (iii) portability of the entire system is still a substantial limitation. While evaluating the whole system for quality and productivity through quantitative survey, cognitive and effective workability were the common issues. Even though many literature surveys and practical studies have been done on this subject, a wide range of industrial adoption was still lacking. This was mainly due to the expensive and bulky toolkits that were not explicitly designed for the design field.

(Schubert et al. 2015) [18] The paper discusses the possible interactive advancements that AR and VR tools can bring, and how their involvement could create better immersive communication among the designers and other users. It emphasizes connecting the two worlds the physical and the digital Design Communication in the form of 2D drawings and details is only comprehendible by the professionals in the field, but not the clients or the laymen constructing the structure. Design decision making at the initial stages becomes easier with illustration drawings which are currently used in the digital format. Now, with the intervention of AR and VR systems it would bring better results. The idea would be to simulate the master plan or the building geometry on a tabletop VR or could also be augmented on the site via headset. The two design components discussed are the collaborative design platform and the onsite AR-applications. The second is discussed based on its potential to grow and evolve, as it is bound to make specific processes of design better.

(Thabet, 2002, updated 2015) [19] The paper discusses the possible prospects of AR involvement in the stage of construction and management, not only to communicate with the skilled labourers but also to get a daily progress report and monitor the working on the site to avoid any deadly accidents. The foremost significant benefit of VR is that the clients can rehearse a building's design experiencing the finished product as if they were in the actual space and the flaws within the designs can also be detected easily. Specific concerns raised were, (i) use of 3D and VR are often beneficial as long as used early at the conceptual design process, (ii) housing developers did not want to expose users to views from sharp unrealistic angles, and (iii) when dealing with local authorities to avoid exposing the design or construction to other issues where an advanced visualization must be used with care. The workers can utilize AR to detect hazardous faults and prevent causalities. Retik and VIRCON are two automated simulations that deal within the 
International Journal on Soft Computing, Artificial Intelligence and Applications (IJSCAI), Vol.10, No.1, February 2021

constructional perspective. The utilization of these tools is to simplify the upcoming intricate designs. The complete analysis of the structure just in case of calamities could be conducted to assess the relief shelter within the particular building.

(Milovanovic, 2017) [20] The paper discusses a wide variation of AR and VR are tools that can be implemented to enhance the ideation process of design, design analysis, presentation and education. It elaborates a wide range of hardware and software systems in the field of AR and VR. This study is a holistic view of the digital world's implication in the field of architecture, which highlighted two aspects of AR and VR design, i.e., interaction and immersion. The initial part discusses the analysis derived from research papers regarding the development of AR and VR in the various design processes and its subsequent implementation. It was observed that maximum research papers were about developing the hardware/software development of the system, followed by design; however, the applications are very few to date. It helps us analyze and understand that we are stuck at the conceptual and design stage due to certain limitations like the cost of technology. The five significant systems elaborated upon this text include; (i) HDM AR- as proposed by the Benchmark system, (ii) HYVE 3D - a system that is an interplay of Computer-Aided Design (CAD) and Virtual Reality, resulting in the formation of VRAD (Virtual Reality Aided Design), making collaborated design in the initial stages feasible, (iii) HMD VR, used in the CAP VR system -The environment proved to enhance students' design quality. Students' immersion in the virtual model of their design augmented their spatial comprehension and enriched their evaluation. However, the communication with the tutors was not seamless because students were wearing an HMD, (iv) Tangible AR - the system illustrated by the Luminous Planning Table, and (v) SDAR or SAR - It utilizes the joint surfaces available to us around like the walls and floors to be used as display devices, providing the design on a 1:1 scale experience.

(Broschart, 2015) [21] The paper on the AR applications discusses the opportunities for better collaboration and immersion of the users in the design projects to achieve enhanced results acceptable to all. It discusses how its involvement is an asset but cannot replace urban planning and architecture's vital processes. It studies the varied tools used or developed for the use of urban planning and architectural visualization. Keeping in mind the various limitations that are foreseen with the use of AR systems (portability of computers and time required for installation), this research lays focus on the smart portable i.e., the mobile phone which consists of fourelement components (1) Computer software generating the 3D model that is to visualize, (2) Geolocating and extracting the exact location data, (3) detecting the user's orientation and (4) the last would overlay these and finally display them. Its diverse applications include: (i) Campus Navigation - Layar tool is utilized to navigate campus with geo-location satellites, (ii) IGA 2017 Berlin - Layar was used to create a digital walk throughout the built area, albeit the system came with barriers. Therefore, RADAR-system (Resource Annotation and Delivery for Mobile Augmented Reality Services) was introduced to breach the barriers and permit the users to place their own location data. Even these apps were limited by the large streaming files and the availability/accessibility of the internet, (iii) Building Culture Saarbrunkrn - to overcome the limitations of the GPS based AR systems, alternative systems based on image recognition tracking systems are also used. "Layar" published a version known as "Layar vision", with its first application being tested in Saarbrunkn. The system was updated with the city street photos of the 1950s, with the colour marking the architectural elements that made the city legible and were in the pre-set time covered with hoardings or destroyed. The experiment was done at various points throughout the city to involve the local people and letting them experience the lost heritage, and what the city aimed to get back, and (iv) Augmented Plan - when it involves the mediation of the plans that we present to the client, most of the information we lay in front is 
International Journal on Soft Computing, Artificial Intelligence and Applications (IJSCAI), Vol.10, No.1, February 2021

tough to comprehend. As a solution to this, apps can take the virtual data such as Plan and augment it within the client's phone itself.

(Redondo et al. 2011) [22] The paper discusses how AR's involvement can change the education and the methods of teaching; enhancing the perception of space and the ability to design in multiple dimensions. Further, the paper elaborates upon the various technologies and the improvements required for before the products are brought into practical use. VR and AR research has shown great potential in the field of design education. However, not much progress has been made in education through these tools due to technical issues and device costs. In Architectural and urban design, the understanding of spaces is an essential component. Currently, this knowledge is achieved during the latter stages of a professional's carrier, while with the help of AR the students can be introduced to these scenarios during the initial part of their course. It will result in a better understanding for the students compared to the traditional tools used to study architecture that is still majorly limited to 2D. It is essential to explain the work process in architecture to juggle between multiple other disciplines to make a project feasible. Traditional representations embody both a need for abstraction and interpretation and can be challenging to understand, possibly misleading those not trained in the field. In response to this, architectural projects and urban design drawings are complemented with perspectives, text and 3D models, both physical and digital. Still, there is a common problem of understanding both spatial qualities and the scale of proposed buildings and structures. In urban design, it becomes vital to have a human-spatial experience; otherwise, project-owners, politicians, decision-makers, and the public often have expectations based on their interpretation that differ from or exceed the realized project's qualities in its context. Changes we need to look forward to (i) before realization, complete 3D models of proposed projects can be studied regarding all aspects. Today we build 3d models, after AR we will be able to experience them and in future maybe make in situ changes, (ii) one can experience simulation of physical conditions changes, animate and visualize pollution, noise, etc., (iii) human factor studies will be made tangible and better outcomes for the design will be achieved, and (iv) public opinion and suggestions could be incorporated as through these tools, design can be accessible to all.

(Van Dessel, 2018-2019) [23] The author discusses the application of VR for the utilization of visualization and communication in a wide range of fields and scale of projects. It deals with architectural project visualization to visualize large scale projects like urban planning, while the comprehension of the project is the same for both professionals and laymen. Virtual Reality deals with a holistically created or designed models; it is well utilized with the augmented Reality which uses real-time location. Traditionally, urban design cardboard is used to create physical models, which is not a very flexible option, and the visualization of the space is done only from a bird-eye view. City Model - creating a virtual model to immerse in the design and make changes along the visualization is one of the main aims of the VR. The main advantage is to see the proportions and height that otherwise cannot be visualized in the 2D GIS system, currently in use.

Three visualization techniques have been adopted (1) - Photorealistic Visualization aims at providing a real like impression of the environment, mainly for the non-experts. The complex geometrical forms of the environment e.g., trees increase the file size and create multiple issues. (2) - Visualization of Information and Data which enables information to be comprehended and immersed with the city model e.g., occupancy, year of construction, etc. (3) - Illustrative and non-photorealistic visualization can be used for creating the first look of the model, providing with the urban information, helping in decision-making process.

City GML - A standard core model that acts as a source of information for multiple disciplines which require urban data. Although the standardized model does provide a clear structure, the 
International Journal on Soft Computing, Artificial Intelligence and Applications (IJSCAI), Vol.10, No.1, February 2021

coding languages are unknown to the urban planners. The work becomes cumbersome and restrictive to the designers.

(Ahmed et al. 2019) [24] The author elaborates upon the adoption of various new and convenient strategies or methodologies to enhance design education for the students and the skilled workers. The recent development in information technology has enormous opportunities to improve the architectural education in terms of methodologies, strategies and tools. Studies explore the importance of using virtual Reality with open-minded and progressive methods in teaching architectural courses and not just stick to the traditional yesteryear methods. The research aimed at evaluating the (BCIVR Software) in architectural education of building construction courses as a case study at Jordan University of Science and Technology (JUST). This Building Construction using Virtual Reality technology (BCIVR) is computer software designed by the authors for research purpose. It presents $4 \mathrm{D}$ models (3D model and time dimension) for certain building construction phases using VR technology to do immersive and non-immersive virtual reality experience for the users in terms of three axes: (i) providing students with the building construction information, (ii) achieving enjoyment, and (iii) integrating with other courses. The data was obtained from architecture students on a structured questionnaire. The results were highly in favour of VR software than those of the traditional teaching methods. In conclusion, the use of BCIVR software as a tool in building construction courses is beneficial and effective for the students. The VR technology can also find application in many other courses offered in the curriculum of Architectural programs. VR integrates the traditional way of education by bringing the real world into the classroom; however, its application in architectural educational purposes has been limited.

(Gębczyńska-Janowicz, 2020) [25] The author discusses the application of AR and VR tools to reconstruct the heritage virtually deteriorated by time and use these to educate the people and students who can no longer visualize or experience the beauty of those monuments. AR is also elaborated as a tool that can show the transition in the cities and their architecture through time. The evaluation of research presented in this article indicated its effectiveness as an educational tool in the architectural design studio to improve learning. Realistic concept visualization enables students to experience the remarkable consequences of proposed solutions. VR can support the design of commemorative places by applying reconstructed buildings to the real image. With virtual Reality, the guide could use tools to create an augmented reality experience, draw attention to specific elements that otherwise may not be easy to explain in real life. CAVE is one such exciting tool for an immersive design environment. VR technology allows architectural design classes based on advanced digital technologies, enabling a broad understanding of concept visualization. VR allows you to see the experience from different points of view and can also be used to generate 3D images of related architectural elements, such as a parapet detail, to assist in a quick and more profound learning experience in understanding architecture and construction. Previously, the critical argument inhibiting the presence of year in education of architectural design was the cost of purchasing technology-related equipment and the difficulty of acquiring skills to operate it. Today, students are fluent in the application of CAD software and graphics processing applications. Students who have experience in computer modelling are becoming increasingly familiar with VR, which helps promote changes in both education and architectural practice.

(Sardo et.al, 2018) [26] The authors discuss the possibilities for enhancing the current AR system from a two sensory system to a multi-sensory system. This is done by exploring the three i.e. feel or touch, smell and taste. The paper adds interesting possibilities that can be worked upon practically in the future. AR is discussed as a tool that immerses a person into an altered reality by connecting with the sight and sound and exploring in incorporating the other three senses that 
International Journal on Soft Computing, Artificial Intelligence and Applications (IJSCAI), Vol.10, No.1, February 2021

have not been as explored as the other two. The multisensory AR is believed to involve a user to experience the better involved experience. The paper develops the interface by centering on a museum, but some can be added to enhance AR experience. The interface system experiments also concentrate on moving from the big computer setups to more portable computer systems that can easily connect with the phone. Simulation for these senses is experimented with users to get results such as the simulation of touch and feel being explored with vibration, thermal simulation and airflow. There are not many options to stimulate the taste sense, but it has been studied that with the help of sight and smell, the sense for taste can also be developed. Vaporization was also a technique utilized to simulate smells. These experiments utilized some previously existing techniques and enhanced them to achieve the desired results. The conceptual model had a great response from the user survey even though it had some shortcomings and can still have better outputs with improvements.

(Megahed, 2014) [27] He discusses the need for a more creative and a prospective study approach with the changing times; the paper discusses how AR's involvement can change the education and the prevailing methods of teaching. Presently, teacher-oriented teaching can be replaced by a student-oriented one. The use of AR is studied for the creative and perceptive development of the students in design. The incorporation of such tools can shift the current teacher-oriented learning to student-oriented learning. However, this incorporation still faces a lot of technological and social challenges. The real-life lessons' pedagogy has been in 2-D for a long time while the real objects itself exist in 3-D. Architectural design education is a field which requires a lot of practical knowledge and new methods to evolve the creativity of the students, with the constant changes coming up in the field of design it becomes essential to adapt, incorporating new techniques. The initial stage of data collection and analysis while experiencing different cities' environment while sitting in the classroom gives a clearer perspective of context. The early stages of a design process involve most of the brainstorming, this stage requires the freedom for visualization and to be able to communicate it at its best. The next stage which incorporates much reviewing and redo's can be made easy with the tools as mistakes can be corrected in real-time on the spot. The paper discusses the working of two software in education, i.e., ARTHUR and AR Workbench.

(Abramovici, 2017) [28] Maintenance is a vital aspect of the post-construction process, which in most cases turns out to be tedious and expensive. This research explores a cloud-based graph interface model to create an effective collaboration among an individual, activities and the team that are connected to the server ( IOT - Internet Of Things ).

Throughout the life-cycle of a building, maintaining the original conditions costs the most. The paper deals with visualizing the maintenance data and incorporates team-wide communication and indicates any warning situations that require coordination. To make things, efficient coordination is developed amongst the machines and humans by using smart devices and the internet of things. The whole concept is based on the graph model (GUI- Graph user interface) that analyses the type of goals and their approach. The model discussed it is a cloud-based system which requires the machines or objects requiring maintenance to be a part of the internet of things (cloud-based system). The model connects with the individual technician leading to activities related to other activities; the sensors record the results and values for follow up activities. The implementation of a prototype of the model was conducted to note the model's workability, although the model could use more organized and holistic planning. The author is now onto the stage of proof of concept. 
International Journal on Soft Computing, Artificial Intelligence and Applications (IJSCAI), Vol.10, No.1, February 2021

\section{DisCuSSION}

Since 1967, with the first research paper published by Schutz and North-Western University (1967)[2], AR and VR have been conceptualized as instruments for architecture and urban design. Since then, numerous developments have been made and, although VR was used for simulation, AR began to be used in indoor environments. The advancement in the workability and application of these instruments from then to now, has been at a very slow rate of development in the operability and deployment of these methods, since this technology has not been developed specifically to fit this specific domain of design. In recent years, however, certain software and hardware have been developed for particular use in the area of architecture, exploring immersive collaboration, real-time simulation and data processing. In ideas and experiments that deal with the ability of the technologies being used to; (i) create an engaging user interface, which provides a presence in your creation and immerses you in the project to feel the project's effect, the spectrum of these methods has been further explored. (ii) To enhance the location and monitoring system in real time. (iv) As part of an academic system, integrating these tools will introduce students to realistic challenges long before becoming proper architects

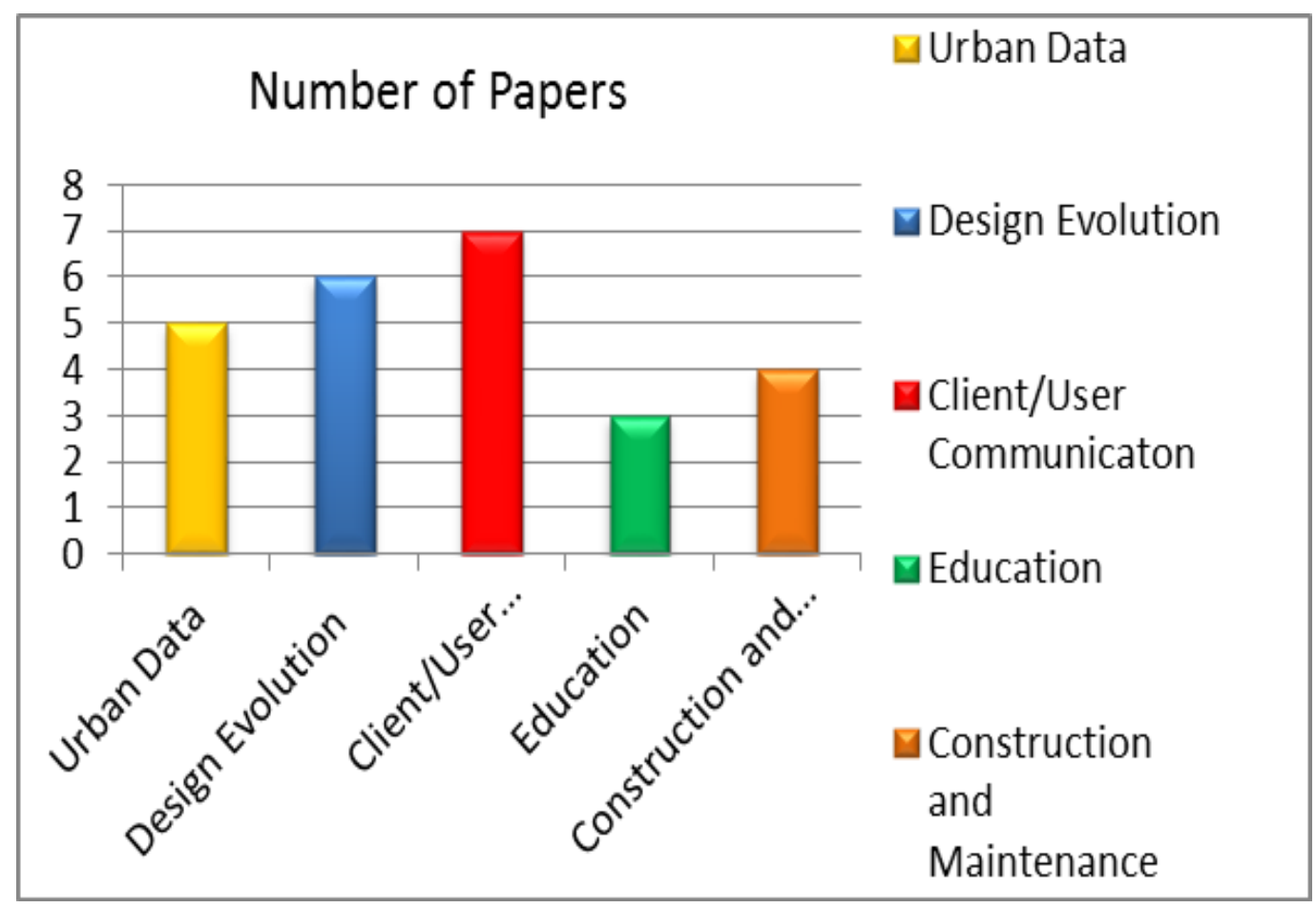

Figure 1.Categorization of AR/VR under diverse sub heads of architecture \& urban design

(v) Transmitting designs to staff is a challenge that leads to many life-threatening causalities and management challenges, but can be reversed by using AR and VR to forecast these problems. (vi) It is possible to observe and imagine deteriorated/dilapidated heritage structures over time.(vii) The intricate urban fabric of the modern age, where all buildings are rising high in the sky and losing identity, being tedious to move across the city, could work wonderfully for them with these visual aided instruments. However, in science and economics, these methods also come with a range of drawbacks. The tools need to be more user-friendly, open to both experts and end-users, and economically feasible. Only after addressing the drawbacks will the mass development of these instruments be seen to take place. 
International Journal on Soft Computing, Artificial Intelligence and Applications (IJSCAI), Vol.10, No.1, February 2021

\section{CONClusion}

The paper summarizes the broad range of options for architecture and urban design that are being created, conceptualized, or used in augmented reality (AR) and virtual reality (VR). The research papers explain the different paths briefly under AR that has the potential of growth or enhancement. Two things that are being discussed in the area of architecture are teamwork and immersion. With the architecture complications introduced by changing time, it becomes necessary to handle these data efficiently to seek optimal performance. For people to learn and build, reading, learning, and sketching are essential, but with AR and VR, a fourth dimension is added to our understanding. The Human-Computer interface is at the beginning of its age and can modify the depth of our perception of spaces and their ergonomics. Currently, architects are now acquainted with $\mathrm{CAD}$ instruments and numerous modelling, research and management techniques that enable architectural architecture to be digitally interpreted and realized before construction by traditional VR technologies. AR brings it to the next stage and requires the physical facts to be incorporated into these virtual visualizations. Continuing future advances in $\mathrm{AR}$ and VR would also play an important role in optimizing the architecture of the urban environment.

\section{ACKNOWLEDGEMENT}

I would like to place my thanks to Prof (Dr) MadhuraYadav, Director,School of Architecture and Design, Manipal University, Jaipur for her guidance and motivation. I also want to thank Dr. Vaneet Jishtu, Scientist, HFRI for help in motivation and guidance.

\section{REFERENCES}

[1] Husserl, E and Gibson, WRB 1931 Ideas: general introduction to pure phenomenology, G. Allen \& Unwin Ltd., London. Pp. 465.

[2] Schutz, A and Northwestern University (Evanston Ill.) 1967 The phenomenology of the social world, Northwestern University Press, Evanston, III.

[3] Norman, D. 1988. The Psychology of Everyday Things, Basic Books, New York.

[4] Frazer, JH, Frazer, JM and Frazer, PA 1980 Intelligent Physical Three-Dimensional Modelling Systems, Computer Graphics 80 Conference, pp. 359-370.

[5] Seichter, Hartmut and Schnabel, Marc Aurel 2005 Digital and Tangible Sensation:

[6] Sørensen, Søren S 2006The development ofAugmented Reality as a tool inArchitectural and Urban designNordic Journal of Architectural Research. Volume 19, No 4, 2006.

[7] Döllner Jürgen, Konstantin Baumann, Henrik Buchholz 2006 Techniques and strategies of visualization complex 3D spatial data. CORP 2006 \& Geomultimedia06. Assessed on 12.011.2020.

[8] Seichter, H 2007 Augmented reality aided design. (Thesis). University of Hong Kong, Pokfulam, Hong Kong SAR. Retrieved from http://dx.doi.org/10.5353/th_b3896659

[9] Wang, Xiangyu(2009). Augmented Reality in Architecture and Design: Potentials and Challenges for Application. International Journal of Architectural Computing. 2009;7(2):309-326. doi:10.1260/147807709788921985.

[10] Abboud, Rana(2014). Architecture in an Age of Augmented Reality:Opportunities and Obstacles for Mobile AR in Design, Construction, and Post-Completion.

[11] Seichter, Hartmut 2020 Benchworks - Augmented Reality Urban Design. CAADRIA (2004). [Proceedings of the 9th International Conference on Computer Aided Architectural Design Research in Asia / ISBN 89-7141-648-3] Seoul Korea 28-30 April 2004, pp. 937-946.

[12] ARtoolkit. http://www.hitl.washington.edu/home/. Assessed on 15.11.2020.

[13] Kim, Mi jeong \& Wang, Xiangyu \& Zhu, Xingquan \& Kang, Shih-Chung (2011). Augmented Reality Research for Architecture and Design. 10.4018/978-1-61350-180-1.ch013. 
International Journal on Soft Computing, Artificial Intelligence and Applications (IJSCAI), Vol.10, No.1, February 2021

[14] Chung, DHJ, Zhiying, SZ, Karlekar, J, Schneider, M, \& Lu, W (2009). Outdoor Mobile Augmented Reality for Past and Future On-Site Architectural Visualizations, Computer Aided Architectural Design Futures. pp.557-571.

[15] Wang, X, \& Dunston, PS (2005). Real Time Polygonal Data Integration of Cad/Augmented Reality In Architectural Design Visualization, Computing in Civil Engineering (American Society of Civil Engineers,ASCE) (pp.1-8).

[16] Santos, P, Gierlinger, T, Stork, A \& McIntyre, D (2007). Display and Renering Technologies for Virtual and Mixed Reality Design Review.Interational Conference on Construction Applications of Virtual Reality. pp.165-175.

[17] Belcher, D, \& Johnson, B (2008). MxR: A Physical Model-Based Mixed Reality Interface for Design Collaboration, Simulation, Visualization and Form Generation.Association for Computer Aided Design in Architecture. pp.464-471.

[18] SchubertGerhard, David Schattel, Marcus Tönnis, Gudrun Klinker, Frank Petzold(2015).Tangible mixed reality on-site Interactive augmented visualisations from architectural working models in urban design. São Paulo, Brazil : s.n., 2015. The Next City - New Technologies and the Future of the Built Environment $-16^{\text {th }}$ International Conference. pp 55-74 .

[19] Thabet, Walid \& Shiratuddin, Mohd Fairuz \& Bowman, Doug (2002). Virtual Reality in Construction. In: Engineering Computational Technology. pp.25-52. Publisher: Saxe-Coburg Publications. March 2002, updated 2015.

[20] Milovanovic Julie, Guillaume Moreau, Daniel Siret, Francis Miguet (2017).Virtual and Augmented Reality in Architectural Design and Education: An Immersive Multimodal Platform to Support Architectural Pedagogy. $17^{\text {th }}$ International Conference, CAAD Futures, Gülen Çağdaş, Mine Özkar, Leman F. Gül and Ethem Gürer, Jul 2017, Istanbul, Turkey.

[21] Broschart, Daniel \& Zeile, Peter(2014). Architecture - Augmented Reality Techniques and Use Cases in Architecture and Urban Planning. [https://www.researchgate.net/publication/269574525] Updated Feburary 2018.

[22] Redondo, Ernest \& Navarro, Isidro \&Riera, Albert \& Fonseca, David (2011). Visual Interfaces and User Experience: Augmented Reality for Architectural Education: One Study Case and Work in Progress. Communications in Computer and Information Science. 166. pp. 355-367.

[23] Anke, Van Dessel(2019). The Use of Virtual Reality in Urban Planning Review paper on the (dis)advantages and a new perspective for future research. Master thesis - Master of Urbanism and Spatial Planning. Center for Urban Development, University of Antwerp.

[24] Ahmad K. Bashabsheh, Hussain H. Alzoubi, Mostafa Z. Ali (2019).The application of virtual reality technology in architectural pedagogy for building constructions. Alexandria Engineering Journal,Volume 58, Issue 2. pp.713-723. ISSN 1110-0168. https://doi.org/10.1016/j.aej.2019.06.002.

[25] Gębczyńska-Janowicz, Agnieszka (2020).Virtual reality technology in architectural education . World Transactions on Engineering and Technology Education. Vol. 18. No. 1. http://www.wiete.com.au/journals/WTE\&TE/Pages/Vol.18,\%20No.1\%20(2020)/04-GebczynskaJanowicz-A.pdf

[26] Sardo, J.D., Pereira, J.A., Veiga, R., Semião, J., Cardoso, P., \& Rodrigues, J. (2018). A Portable Device for Five Sense Augmented Reality Experiences in Museums.

[27] Megahed. N.A.(2014). Augmented Reality Based - Learning Assistant for Architectural education. Megahed discusses the need for a more creative and a perspective studying approach with the drastic changing times, the paper discusses how the involvement of AR can change the education and the methods of teaching. The present scenario teacher oriented teaching can change to student oriented.

[28] Michael Abramovici, Mario Wolf, Stefan Adwernat, Matthias Neges (2017). Context-aware Maintenance Support for Augmented Reality Assistance and Synchronous Multi-user Collaboration,Procedia CIRP,Volume 59;pp. 18-22

\section{AUTHORS}

\section{Pearl Jishtu}

Presently pursuing her final year in Bachelor of Architecture, at Manipal University Jaipur.Finds motivation towards research work, in the role of technology in architecture. She has held positions of responsibility and has represented the University at National Association of Students of Architecture.

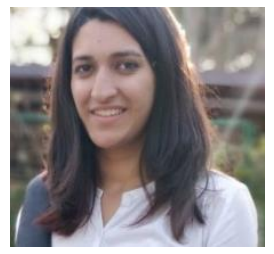


International Journal on Soft Computing, Artificial Intelligence and Applications (IJSCAI), Vol.10, No.1,

Prof (Dr) Madhura A Yadav

February 2021

An Architect-Planner with over 25-year experience.She is Founder Head of the School Architecture \& Design and now Director of SA\&D at Manipal University Jaipur. She is one of the founder members in establishing Faculty of Design at Manipal University Jaipur and founder head for fashion Design, Interior Design and Planning programmes. She is/was on several Committee/Expert Groups set up by Government of India., She is on Jury of various Architectural competitions.Sheis also on Editorial Board Architecture, Urban Design and Urban Planning India Journals.

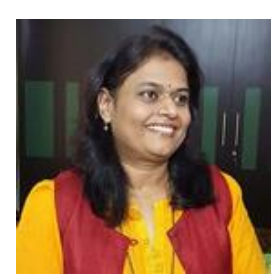
She has published number of papers in national and international journals and conferences. She is UNESCO certified Mentor for Community based participatory research.She is Indian Green Building Accredited Professional. She has conducted workshops/conferences on Waste Management, Bamboo Architecture, Earthquake Resistant Structures, Sustainable Cities/ buildings etc. Her current research interests are Architecture- Ecology interface and Eco- cities, Promotion of eco materials and Community Based Participatory Research. She is recipient of Distinguished Faculty in Architecture Award 2017 and Educational Leadership Award 2019. 